\title{
Balkanologie
}

Balkanologie Revue d'études pluridisciplinaires

Vol. II, nº 2 | 1998

Volume II Numéro 2

\section{Pribičević (Ognjen), Vlast i opozicija u Srbiji (Le pouvoir et l'opposition en Serbie)}

Beograd : Radio B92, 1997, 169 p.

\section{Yves Tomić}

\section{(2) OpenEdition}

\section{Journals}

Édition électronique

URL : http://journals.openedition.org/balkanologie/273

DOI : 10.4000/balkanologie. 273

ISSN : 1965-0582

\section{Éditeur}

Association française d'études sur les Balkans (Afebalk)

Édition imprimée

Date de publication : 1 décembre 1998

ISSN : 1279-7952

\section{Référence électronique}

Yves Tomić, "Pribičević (Ognjen), Vlast i opozicija u Srbiji (Le pouvoir et l'opposition en Serbie)»,

Balkanologie [En ligne], Vol. II, n² 2 | 1998, mis en ligne le 03 juin 2008, consulté le 17 décembre 2020. URL : http://journals.openedition.org/balkanologie/273 ; DOI : https://doi.org/10.4000/balkanologie. 273

Ce document a été généré automatiquement le 17 décembre 2020.

(C) Tous droits réservés 


\section{Pribičević (Ognjen), Vlast i opozicija u Srbiji (Le pouvoir et l'opposition en Serbie)}

Beograd: Radio B92, 1997, 169 p.

\section{Yves Tomić}

\section{RÉFÉRENCE}

Pribičević (Ognjen), Vlast i opozicija u Srbiji (Le pouvoir et l'opposition en Serbie), Beograd : Radio B92, 1997, 169 p.

1 L'auteur, politologue travaillant à l'Institut des Sciences sociales de Belgrade, tente de définir les causes de l'“exception serbe" et les raisons de la domination du Parti socialiste de Serbie (SPS) dans la vie politique du pays. En effet, la Serbie constitue un cas particulier par rapport à l'ensemble des anciens pays communistes connaissant un processus de transformation politique et économique tendant vers l'instauration d'une société pluraliste et ouverte, dans la mesure où il n'y a pas eu de rupture entre l'élite politique de l'ancien système et le nouveau instauré en 1990.

2 La première raison du maintien au pouvoir des anciens communistes provient de l'adoption du nationalisme à partir de 1987 qui a permis une relégitimation du Parti (Ligue des communistes de Serbie). Les succès électoraux du SPS s'expliquent par le soutien de certains groupes sociaux : travailleurs manuels, retraités, paysans, militaires et couches de la population les moins éduquées. La troisième raison réside dans la promptitude du pouvoir à défendre fermement l'ordre établi. Enfin, la force du régime peut s'expliquer par le caractère pragmatique de la politique de Slobodan Milošević : passage du communisme au nationalisme, d'une politique belliqueuse à une politique pacifiste (adoption du plan Vance-Owen en 1993, des accords de Dayton en novembredécembre 1995). En outre, le SPS a su tirer profit de son statut de parti gouvernant en assurant le contrôle et en abusant de l'appareil d'État. Ni la situation économique 
catastrophique, notamment en 1993, ni la rupture avec les dirigeants de la République serbe de Bosnie, ni la la chute de la Krajina en août n'ont ébranlé le pouvoir de Slobodan Milošević. Ognjen Pribičević expose également les faiblesses de l'opposition serbe qui a dû se constituer et se structurer dans les conditions particulières de la guerre et des sanctions de l'ONU à l'égard du pays. Selon l'auteur, les principales raisons des échecs électoraux de l'opposition résident dans l'absence d'unité, sa fragmentation, l'absence de programme alternatif clair, les revirements politiques répétés et la concurrence âpre entre les différents leaders des partis oppositionnels. L'auteur analyse également l'ascension et la chute de l'extrême-droite (Parti radical serbe de Vojislav Šešelj). Cette dernière a pu opérer une percée en Serbie grâce à la politique nationaliste de S. Milošević, à la guerre et aux sanctions économiques. Le Parti radical serbe, allié au SPS, a exécuté la "sale besogne" dans les conflits en Croatie et en Bosnie-Herzégovine et a contribué à la destruction de l'opposition en Serbie. L'auteur associe l'essor du Parti radical à la volonté politique des socialistes serbes et présage un affaiblissement de ce parti extrémiste. Ces prévisions ont eté trahis par les faits, puisque le parti de Vojislav Šešelj, en opposition avec les socialistes avant d'entrer dans un gouvernement de coalition avec eux en 1998 a montré qu'il était une formation importante sur l'échiquier politique serbe indépendamment des stratégies d'alliance et de dénigrement du Parti socialiste serbe. Aucun travail sérieux, semble-t-il, n'a été réalisé sur le développement de ce parti nationaliste et extrémiste. O. Pribičević tente ensuite de définir quel est le meilleur système politique pour la Serbie: systèmes parlementaire et présidentiel. De la même façon, il décrit les atouts et les défauts de la démocratie majoritaire et consensuelle. Selon lui, la culture politique autoritaire du pays tend vers le pouvoir fort d'un seul homme. Toutefois, en raison de la structure nationale complexe de la Serbie, le régime parlementaire serait plus approprié. L'auteur analyse ensuite la vie politique du pays après la signature des accords de paix de Dayton en 1995 : les élections fédérales et municipales de novembre 1996. Dans la dernière partie de l'ouvrage, il aborde des problèmes communs aux pays postcommunistes : faibles traditions démocratiques et société civile peu développée. 